\title{
Coexistence of plant species under harsh environmental conditions: an evaluation of niche differentiation and stochasticity along salt marsh creeks
}

\author{
Daehyun $\mathrm{Kim}^{1,2^{*}}$ and Sewon Ohr
}

\begin{abstract}
Background: Ecologists have achieved much progress in the study of mechanisms that maintain species coexistence and diversity. In this paper, we reviewed a wide range of past research related to these topics, focusing on five theoretical bodies: (1) coexistence by niche differentiation, (2) coexistence without niche differentiation, (3) coexistence along environmental stress gradients, (4) coexistence under non-equilibrium versus equilibrium conditions, and (5) modern perspectives.

Results: From the review, we identified that there are few models that can be generally and confidently applicable to different ecological systems. This problem arises mainly because most theories have not been substantiated by enough empirical research based on field data to test various coexistence hypotheses at different spatial scales. We also found that little is still known about the mechanisms of species coexistence under harsh environmental conditions. This is because most previous models treat disturbance as a key factor shaping community structure, but they do not explicitly deal with stressful systems with non-lethal conditions. We evaluated the mainstream ideas of niche differentiation and stochasticity for the coexistence of plant species across salt marsh creeks in southwestern Denmark. The results showed that diversity indices, such as Shannon-Wiener diversity, richness, and evenness, decreased with increasing surface elevation and increased with increasing niche overlap and niche breadth. The two niche parameters linearly decreased with increasing elevation. These findings imply a substantial influence of an equalizing mechanism that reduces differences in relative fitness among species in the highly stressful environments of the marsh. We propose that species evenness increases under very harsh conditions if the associated stress is not lethal. Finally, we present a conceptual model of patterns related to the level of environmental stress and niche characteristics along a microhabitat gradient (i.e., surface elevation).
\end{abstract}

Conclusions: The ecology of stressful systems with non-lethal conditions will be increasingly important as ongoing global-scale climate change extends the period of chronic stresses that are not necessarily fatal to inhabiting plants. We recommend that more ecologists continue this line of research.

Keywords: Niche differentiation, Niche breadth, Niche overlap, Environmental stress gradient, Point bar, Salt marsh

\footnotetext{
* Correspondence: biogeokim@snu.ac.kr

1Department of Geography, Seoul National University, Seoul, South Korea

${ }^{2}$ Institute for Korean Regional Studies, Seoul National University, Seoul, South

Korea
}

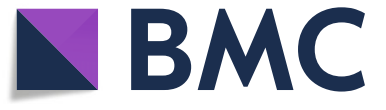

(c) The Author(s). 2020 Open Access This article is licensed under a Creative Commons Attribution 4.0 International License, which permits use, sharing, adaptation, distribution and reproduction in any medium or format, as long as you give appropriate credit to the original author(s) and the source, provide a link to the Creative Commons licence, and indicate if changes were made. The images or other third party material in this article are included in the article's Creative Commons licence, unless indicated otherwise in a credit line to the material. If material is not included in the article's Creative Commons licence and your intended use is not permitted by statutory regulation or exceeds the permitted use, you will need to obtain permission directly from the copyright holder. To view a copy of this licence, visit http://creativecommons.org/licenses/by/4.0/ 


\section{Background}

\section{General overview}

Understanding the mechanisms that maintain species coexistence has long been one of the fundamental goals in plant community ecology (Adler et al. 2007; Chase and Myers 2011; Weiher et al. 2011; Tuomisto et al. 2012; Fukami 2015). A tendency to equate (or at least approximate) coexistence to biological diversity (Chesson 2000) makes such an understanding increasingly urgent in this era of rapid environmental change, where the productivity, diversity, and stability of many ecological system is being reduced (McCann 2000; Hooper et al. 2005; Tilman et al. 2006; Ives and Carpenter 2007; Mougi and Kondoh 2012).

Here, we are broadly concerned with patterns and mechanisms of plant species coexistence under very harsh environmental conditions in a coastal salt marsh system. Harsh conditions can drive coexistence-related processes, such as biological interactions (e.g., predation, competition, and facilitation), ecological succession, dispersal, speciation, and resource partitioning. In this time of rapid climate change, many ecosystems are experiencing profound alterations to ambient physical conditions, which can increase the influences of harshness on inhabiting organisms. An example is found in coastal areas where recent sea-level anomalies have led to the increased frequency, duration, and depth of submergence by saline water (Morris et al. 2002; FitzGerald et al. 2008; Nicholls and Cazenave 2010; Sallenger et al. 2012). Similar climatic effects include extended dry periods in arid environments (Holmgren et al. 2006; Seager et al. 2007; Jiménez et al. 2011) and increased fire activities in the western US forests (Westerling et al. 2011). We propose that it will become increasingly important to understand the mechanisms of species coexistence under highly stressful conditions in order to fully understand plant community structure and function, and to develop appropriate management strategies (Callaway et al. 2002; Kelly and Goulden 2008; Anderegg et al. 2013; Walter et al. 2013).

Numerous investigations have been conducted to enhance our knowledge of the patterns and mechanisms of species coexistence, in the contexts of biological interactions among different species and environmental stress gradients (Wright 2002; Silvertown 2004; Tokeshi 2009; Siepielski and McPeek 2010; Gravel et al. 2011; Cho et al. 2019; Jung et al. 2019). As a result, there are more than 100 denominated theories developed from various ecological systems (Palmer 1994). An exhaustive review of these ideas is not the aim of this paper. Rather, we focused on a few contending but related theories that are relevant to both harshness and the particular environmental setting of the study system (see "Study area" section). For example, the intermediate disturbance hypothesis (Connell 1978) may not be a robust model because we investigated a marsh system that is very stressful but experiences little influence from disturbance events. In addition, given the absence of significant herbivores at the marsh, theories associated with predation are not explicitly considered.

\section{Theory I: coexistence maintained by niche differentiation}

The most widely accepted theory on species coexistence in traditional plant ecology is based on a simple statement, only those species differing sufficiently in resource use can coexist, a corollary of which is, two (or more) species cannot coexist in the same niche (Gause 1934). This theory appears to be adopted by many scientists as a paradigm (e.g., Silvertown 2004; Mason et al. 2011; cf. Tilman 2004), rather than merely as a hypothesis. It is even considered "perhaps the only specific principle or law of nature ever to be proposed in ecology" (Vandermeer 1972: p. 110)The core of niche theory lies in the concept of competitive exclusion. In accordance with Darwin (1859) and Gause (1934), classic ecologists, such as Hutchinson (1959), May and MacArthur (1972), Pianka (1974), Whittaker (1977), and Diamond (1975), suggested that competition plays a major role in determining community structure and diversity by impeding species coexistence. In order to coexist in a same habitat, species should differ in their utilization of resources (e.g., nutrients, water, light), so that they avoid some critical level of interaction. This difference in resource demand has been termed character displacement (Brown and Wilson 1956; Hutchinson 1959), limiting similarity (MacArthur and Levins 1967; Abrams 1983), species packing (MacArthur 1972), or more often, niche differentiation (or diversification, separation, divergence; Connell 1978). If niche differentiation is not achieved, competitive exclusion will eventually hamper species coexistence. Three conditions are required to meet such a case (Aarssen 1989):

- the demands of two species on resources sufficiently exceed the supply

- the two species make demands on a sufficiently similar set of resource units

- one of the species possesses a sufficiently greater competitive ability for these particular resource units.

\section{Theory II: coexistence without niche differentiation}

In the 1970s, some ecologists began to doubt the validity of the niche-based idea, that is, the concepts of competitive exclusion and niche differentiation. This new view was prompted by two factors. First, there was serious lack of empirical evidence that articulated whether coexistence was truly maintained only by 
niche differentiation, and whether competitive exclusion (and also reduced coexistence) was inevitable if niche differentiation was not sufficient (Wiens 1977; Mahdi et al. 1989; Holyoak and Loreau 2006; Leibold and McPeek 2006; Clark 2009). Specifically, few studies have provided clear-cut data showing that the degree of niche separation is compatible with the observed number of species (but see Russell et al. 1985).

Second, the coexistence of plant species in a certain habitat might be considered not in the context of niche differentiation but, paradoxically, niche overlap (i.e., coincident utilization of one or more resources by two or more species, sharing resources). Higher plants are generally immobile, and thus lack any real choice in resources. By and large, they make demands on virtually the same resources, such as light, nutrients, and water. Therefore, one can justifiably assume that there could be significant overlapping of niches among the coexisting species in many plant communities. If a group of species occur together, it is very likely that they are ecologically and functionally similar (i.e., niches overlap) because, otherwise, they would not have adapted to the habitat and coexisted in the first place. These similarities imply comparable morphology, height, expected life time, and rate of seed production, which in turn would result in similar abilities among the coexisting species to compete for resources (Ågren et al. 1984). This view of retarded competitive exclusion and continued species coexistence due to similar competitiveness has long been conceptualized as competitive combining ability (Aarssen 1983, 1989, 1992) and balanced competition (Zobel 1992).

Aarssen $(1983,1984)$ tried to put this issue into an evolutionary perspective. Basically, he argued that natural selection processes enhance relative competitive ability rather than niche differentiation, thereby maintaining a balance of competitive abilities for contested resources among species. By this logic, individuals of a superior species, instead of outcompeting those of an inferior counterpart, suppress themselves through intraspecific competition. In the meantime, the weaker competitors increase their fitness, which eventually leads to a reduced difference in the relative competitive abilities between the two species (see also Stoll and Prati 2001; Vellend 2006; Fridley et al. 2007; Whitlock et al. 2007; Silvertown et al. 2009). Below is a part of Aarssen's (1983, p. 725) conclusion:

All biological attributes of a species will play a part in determining its niche requirements..., and its relative competitive ability for those requirements... niche requirements generally overlap broadly in plants,...coexistence is permitted because there are numerous possible permutations and combinations of biological attributes in plants which are roughly equivalent in the overall competitive power...these attribute complexes are continually adjusted in an ongoing process of coevolution in which local neighborhoods are constantly engaged in a finetuning process...Consequently, natural selection ultimately maintains a balance of overall relative competitive abilities between two species for essentially the same contested resources.

Species' engagement in the fine-tuning process (i.e., localized competition sensu Shmida and Ellner 1984) implies that they do not necessarily avoid competition to avoid competitive exclusion. Similar doubts about the robustness and general applicability of niche differentiation and competitive exclusion were also raised by Grubb (1977); regeneration niche), Shmida and Ellner (1984); stable coexistence of trophically equivalent species), and Hubbell (2001); unified neutral theory of biodiversity). In particular, Hubbell's (2001) neutral theory assumes all species to be demographically and ecologically identical. Hence, the structure of community assembly arises mainly from neutral stochastic processes, such as dispersal, chance colonization, random extinction, ecological drift, and priority effects (Bell 2000; Holyoak and Loreau 2006; McGill et al. 2006; Mutshinda and O'Hara 2011). Aarssen and Hubbell have long agreed that their theories amount to essentially the same thing in terms of accounting for why species are able to coexist (Aarssen personal communication via e-mail April 5, 2019).

\section{Theory III: coexistence along environmental stress gradients}

Environmental stress models (e.g., Menge and Sutherland 1987; Bruno et al. 2003; Scrosati and Heaven 2007) recognize that the level of physical stress significantly affects the behavior of individual species, modes of biological interactions, and eventually, patterns of species coexistence and diversity in a plant community. One traditional belief in this regard has been that competition should be more intense in the benign and productive side of an environmental gradient, whereas the intensity decreases toward harsh conditions (i.e., stress gradient hypothesis; Bertness and Callaway 1994; Maestre et al. 2009; Holmgren and Scheffer 2010; Lee et al. 2018a, 2018b). In the former case, a (few) strong competitor(s) will outcompete inferior ones, thereby resulting in low-level diversity. In the latter, very high stresses allow only highly tolerant species to survive (i.e., reduction of species pool), and thus, species diversity is expected to be low. Intermediate-level harshness is predicted to compromise these two extreme situations and maximize biodiversity because a certain level of 
stresses prevents a superior competitor from monopolizing available resources, and such stresses secure space for stable populations of inferior species. In sum, retarded competitive exclusion because of physical harshness has been considered a major factor contributing to the maintenance of species coexistence (Grime 2001; Hart and Marshall 2013). Indeed, this notion provides the basis for influential classical theories of non-equilibrium coexistence, such as patch dynamics (Pickett 1980), the intermediate disturbance hypothesis (Connell 1978), and Huston's (1979) dynamic equilibrium model.

There are at least two theories associated with niche differentiation, indicating that one can observe high biodiversity even under highly stressful conditions. First, Tilman's (1985) resource-ratio hypothesis suggests that high-level species coexistence can be achieved at low resource levels because the coexisting plants experience their environment as inherently spatially variable more than at high levels of resources. In a somewhat different context, Chesson and Huntly (1997) propose that stable coexistence may result easily from classical resource partitioning when strong environmental harshness makes existing tolerant species more equal in demographic rates. They conclude that, although harshness itself cannot stabilize species coexistence, it may facilitate or broaden the effects of other diversity-stabilizing mechanisms, such as resource partitioning and niche differentiation. In addition, facilitative biological interactions can be another important mechanism of species coexistence under environmental harshness (He and Berness 2014), as has been demonstrated in salt marshes (Bertness and Shumway 1993), arid ecosystems (Maestre and Cortina 2004), and alpine ecosystems (Callaway et al. 2002).

\section{Theory IV: coexistence under non-equilibrium versus equilibrium conditions}

Most of the environmental stress models discussed above exhibit one common characteristic that an important (and often imperative) component is the role of disturbance in shaping community structure and patterns of species diversity. Such a strong emphasis on disturbance implies that species coexistence is maintained under non-equilibrium states, in which disturbance events are frequent and strong enough to prevent a system from returning to its previous ecological phase before another disturbance event occurs (Connell 1978; Chesson 2000; Araújo and Pearson 2005). Consequently, a question arises concerning the general applicability of current theories of coexistence to communities that exhibit stressful conditions but limited and infrequent disturbances, that is, communities where a degree of equilibrium might be attained.

Many theorists have been optimistic that disturbancerelated models will be applicable to many different types of communities (but see Fox 2013). However, for example, Locke's (1992) classic analyses of zooplankton communities along $\mathrm{pH}$ gradients (i.e., acidification stress) did not support such an expectation. She argued that it is questionable whether the level of physical disturbance included in the conventional models is comparable to the actual level of stresses that plant species perceive and respond to (see also reviews by Mackey and Currie 2001; Hughes et al. 2007). In short, the traditional disturbance-based models may not be robust if species in a system experience non-lethal environmental harshness.

\section{Theory V: modern perspectives}

Although the validity of niche theory has been recognized in community ecology, it also has limitations. First, it is suggested that the niche itself is an abstract concept (Chase and Leibold 2003; Araújo and Guisan 2006; Soberón and Nakamura 2009). Ambiguities in the original formulation of fundamental and realized niche concepts often result in conflicting interpretations as to what is truly a niche in the ecological system (Araújo and Guisan 2006). Furthermore, niche theory assumes the existence of stable conditions in, for example, required resources for species, but whether such conditions actually exist or are readily detectable in reality remains elusive (Torres 1984).

Neutral theory has also faced several criticisms, arising mainly from its assumption that species are functionally equivalent and thus all individual species within a community have the same chances of reproduction and mortality regardless of their characteristics (Theory II: coexistence without niche differentiation). In real-world communities, many species exhibit large differences in traits. Therefore, if neutrality holds, these differences should be prone to fitness-equalizing tradeoffs, which is extremely unlikely (Purves and Turnbull 2010). In addition, as Hubbell (2001) acknowledged, stochastic processes associated with neutral theory do not predict coexistence patterns well at local spatial scales (Jabot and Chave 2011; Pos et al. 2019). Related to this is the question of whether perceived neutral processes might result from non-neutral mechanisms (Alonso et al. 2006). This is because neutral theory aggregates and averages the information on community assembly processes across sites, and this will blur deterministic mechanisms, making them appear as neutral dynamics (Clark 2012). However, in the last two decades, the neutral theory perspective has often been used to explain community assembly especially at regional scales (Chave 2004; Rosindell et al. 2011, 2012; Black and McKane 2012; Chesson 2013; Matthews and Whittaker 2014; D'Andrea and Ostling 2016). In addition, due to its simplicity and tractability, the theory still serves as a useful 
null hypothesis for complex biodiversity patterns (Rosindell et al. 2012; Matthews and Whittaker 2014; Munoz and Huneman 2016).

Despite its drawbacks in assumption, prediction, and measurement (Pocheville 2015), niche theory has also advanced in the new millennium (Adler et al. 2007; HilleRisLambers et al. 2012; Matthews and Whittaker 2014; Munoz and Huneman 2016; Letten et al. 2017; Barabás et al. 2018). Ambiguous definitions of niches have been redefined through quantitative approaches of modern coexistence theory (Chesson 2000; Letten et al. 2017). Modern coexistence theory is based on the Lotka-Volterra model and examines community structure in relation to the influence of environmental factors on species interactions (Chesson 2000, 2013; Adler et al. 2007; Ellner et al. 2019). In a theory-based model, complex interactions between species in a community are simplified into competition coefficients, which reflect intra- and inter-specific effects on per capita growth rate (Letten et al. 2017). Under modern coexistence theory, niche and fitness differences are controlling factors that allow species to coexist in the same community. The niche difference is part of a stabilizing mechanism that differentiates niches among species within a community to decrease competition and thus optimize the chance of survival. On the contrary, the equalizing mechanism balances fitness differences between species, thereby contributing to species coexistence (HilleRisLambers et al. 2012). The stabilizing niche differences can be reduced as the average fitness differences decrease. In other words, when niche differences are larger than relative fitness differences, species in a community can stably coexist (Chesson 2000).

Contemporary niche theory is developed from the consumer-resource model (Tilman 1982) and provides an explicit basis for coexistence (Chase and Leibold 2003). While Tilman's model focuses on the dynamics of the consumer-resource system, Chase and Leibold (2003) expand the range of this model from interactions between biotic factors to interactions between biotic and abiotic factors (Letten et al. 2017). A major difference between modern coexistence theory and contemporary niche theory lies in the ways they define niche. For modern coexistence theory, boundaries of niches are defined through an interaction between two or more species. Under contemporary niche theory, in contrast, niches indicate particular traits of an individual species, and the niches of multiple species within a community can sometimes overlap.

In recent years, there has been a growing body of researchers trying to integrate the niche and neutral perspectives (Adler et al. 2007; Chisholm and Pacala 2010; Pigolotti and Cencini 2013; Kalyuzhny et al. 2015). In particular, a number of studies have demonstrated theoretically and empirically that both niche-based stabilizing mechanisms and neutral-based equalizing mechanisms appear to operate simultaneously along the continuum of environmental stress gradients in many ecological systems (Gravel et al. 2006; Mutshinda and O'Hara 2011; Jeraldo et al. 2012; Matthews and Whittaker 2014; Scheffer et al. 2018; Ellner et al. 2019; Kim 2019). Accordingly, the focus today is increasingly on understanding the relative importance of these two mechanisms for species composition and diversity under different environmental conditions (Smith and Lundholm 2010; Chase and Myers 2011; Tuomisto et al. 2012). In particular, it is recently proposed that deterministic processes gain importance and stochastic processes lose importance as a community enters a regime of more stressful conditions (e.g., Chase 2007, 2010; Guo et al. 2014; cf. Lepori and Malmqvist 2009). That is, if a system is under harshness, only a small subset of the regional species pool can pass through the associated environmental filters. Because the resulting species richness is low, the probability of ecological drift will reduce, leading to a community likely assembled by nichedriven processes (i.e., weak stochasticity) (Kim 2019).

\section{Summary}

This review of the major coexistence theories provides four insights. First, there are few general models that can be applied to many ecological systems with convincing results. Even the widely accepted niche differentiation hypothesis has faced strongly opposing viewpoints (especially from the competitive combining ability hypothesis) over decades. The contrasting theories of niche differentiation and competitive combining ability (or neutrality) are the key interests of this present work. Second, the lack of general models implies that ecologists are still far from understanding the mechanisms of species coexistence under harsh environmental conditions. Much remains to be discovered (e.g., coexistence by or without niche differentiation), beyond the hypothesis that the intensity of competitive interactions weakens near the stressful end of physical gradients. Third, due to the conventional emphasis on disturbance, stressful systems with non-lethal conditions have not received the attention they deserve. The ecology of such systems will be increasingly important as global climate change extends the period of chronic stresses that are not necessarily fatal to inhabiting plants. Finally, for decades, theories have been presented, but further empirical insights are required based on field data to test the various coexistence models at different spatial scales and in different ecosystems. We do not claim that our current research resolves these four issues. Rather, this paper provides a set of observational species composition data from a single marsh system, in which plant 
communities experience non-lethal stresses along an environmental gradient; it should be considered a springboard for more extensive experimental research in various ecological systems.

\section{Hypothesis}

In this research, we address a fundamental question, what are the patterns and possible mechanisms of plant species coexistence under very harsh but non-lethal environmental conditions? To rephrase, the community to be tested is not directly influenced by high-magnitude disturbing forces but shows a certain level of "well-defined, autogenic developmental trends" (Odum 1985). We broadly hypothesize that there will be an overall trend in species diversity along environmental stress gradients at the study marsh. In particular, following the general explanations of the environmental stress models explained above (Theory III: coexistence along environmental stress gradients), we expect that the highest diversity will be observed at the intermediate-level stresses along the environmental gradient we examine. However, this hypothesis might be rejected if, for example, we observe unexpectedly high species diversity even under very stressful conditions.

Pianka (1974), in his classic niche overlap hypothesis, predicted that the maximum tolerable niche overlap between two species should be an inverse function of the intensity of inter-specific competition. Therefore, both decreasing overlap (i.e., niche differentiation) and increasing species diversity will indicate highly intense diffuse competition (i.e., native species in a community compete among themselves). A corollary of this idea is that high-level species diversity implies high-level diffuse competition (MacArthur 1972), which in turn significantly lowers niche overlap (see also Russell et al. 1985; Silvertown 2004). We embody these ideas as a conceptual model along a resource gradient at different levels of species diversity (Fig. 1). In the model, we hypothesize that high diversity is maintained by niche differentiation and is associated with intense diffuse competition. In the case of low diversity, reduced competition allows niche overlap (i.e., resource sharing) to increase. Assuming that the three systems with different levels of species diversity in the model possess the same extent of resource niches, we expect that niche breadth should be high where diversity is low and low where diversity is high. Niche breadth is a measure of the evenness of resource utilization by species along given niche dimensions (Levins 1968). High and low niche breadths (i.e., high and low evenness) are, therefore, indicative of generalist and specialist species, respectively (Vandermeer 1972; Gravel et al. 2006; Finke and Snyder 2008).

\section{Materials and methods \\ Study area}

The study area is a barrier spit, located on the Skallingen peninsula in southwestern Denmark (Fig. 2a). It is characterized by geomorphological zonation typical of the Wadden Sea islands. From the ocean (west) to the backbarrier lagoon (east), the depositional sequences are as follows: beach, dune, salt marsh, and tidal flat. The southwest-facing beach and sand dune of the spit are directly influenced by westerly storm surges that often cause erosion and loss of habitat. However, the backbarrier salt marsh is sheltered from the effects of such destructive events, as the surge waves pass through a relatively narrow tidal inlet between the southern end of the peninsula and an island, Fanø, so most wave energy is lost before they arrive at the backbarrier shoreline (Kim et al. 2011a). Even during storms, the wave climate at the backbarrier area of Skallingen is relatively calm (Bartholdy and Aagaard 2001; Kim et al. 2011b, 2013). The area is classified as micro-tidal: the tidal range is about $1.7 \mathrm{~m}$ at spring and $1.3 \mathrm{~m}$ at neap tides with a mean of $1.5 \mathrm{~m}$.

The main focus of this research was on plant species coexistence under very harsh physical conditions. While salt marshes themselves are conventionally considered stressful environments (Adam 1990; Bertness et al. 2001), even these systems include high locations with relatively benign conditions (i.e., low frequency of sea water inundation), allowing less tolerant inland plants to

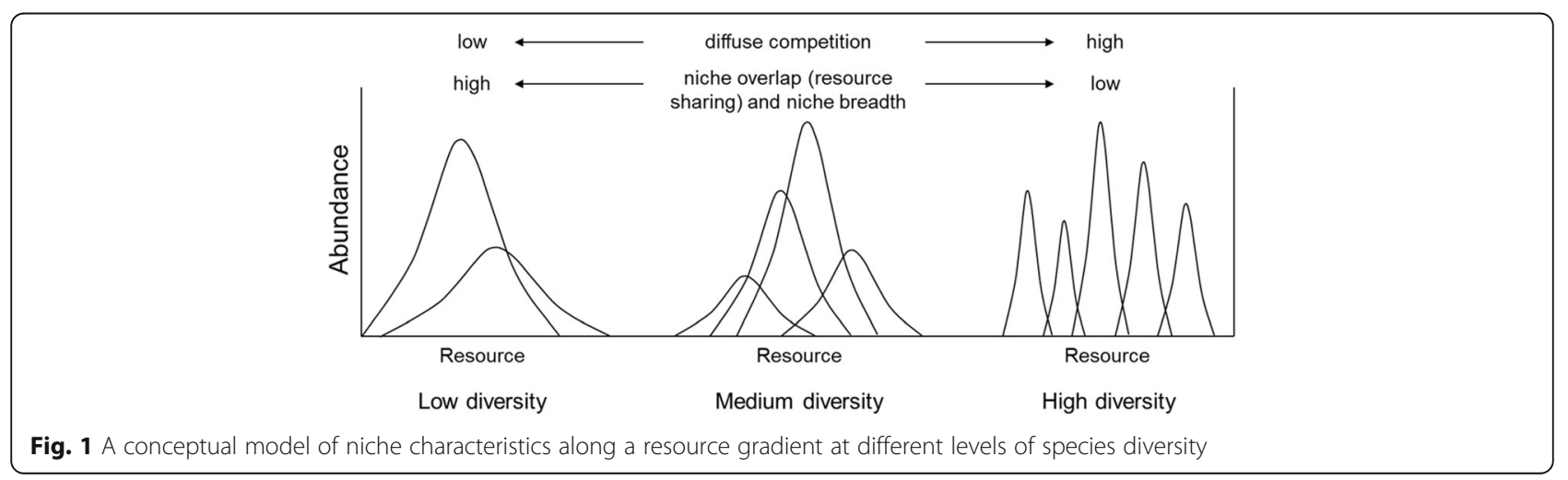




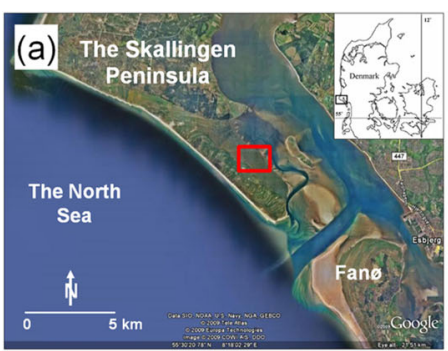

(c)
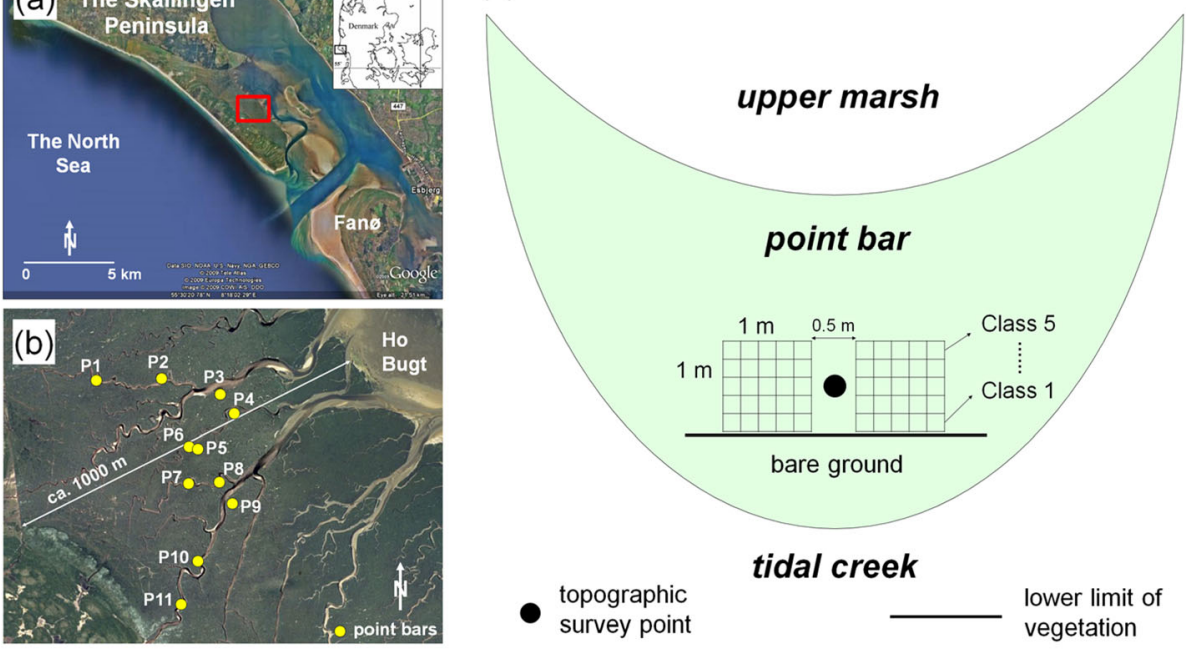

\section{tidal creek} $\begin{array}{ll}\text { topographic } & \begin{array}{l}\text { lower limit of } \\ \text { vegetation }\end{array}\end{array}$

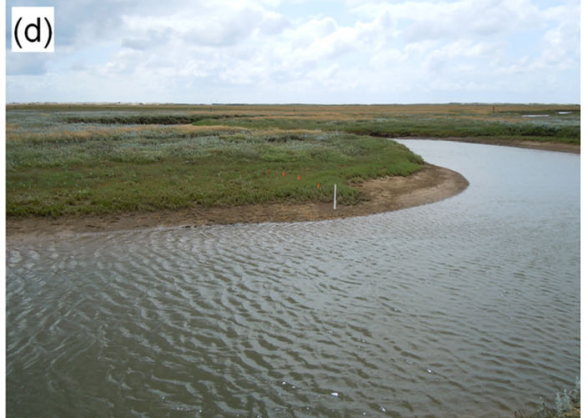

(e)

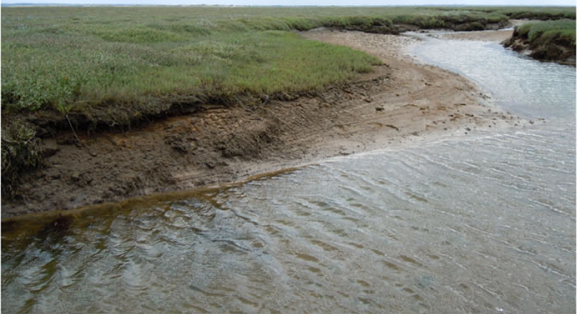

Fig. 2 a The location of the Skallingen salt marsh in southwestern Denmark. The inset indicates $\mathbf{b}$ showing the distribution of 11 point bars selected across the marsh. $\mathbf{c}$ Sampling design at each bar. $\mathbf{d}$ and $\mathbf{e}$ are the photos of P4 and P5, respectively

establish. Therefore, we restricted our interest to point bars of tidal creeks that experience frequent inundation by saline water during bidirectional tidal flows. The Skallingen marsh has a natural tidal creek system across its platform (Kim et al. 2010; Kim 2018). Considering the creek's continuous migration at Skallingen (Kim 2012, 2014), the importance of tidal creek processes to the whole marsh ecology is expected to grow. Moreover, there are a variety of point bars shaped by fluvial-geomorphic processes, and these bars show varying sizes and sinuosity. In this regard, we consider that the marsh provides a good laboratory for studying plant species coexistence and diversity in very stressful tidal channel conditions.

Previous literature has identified some potential disturbing forces around creek banks, such as wrack deposition that smothers underlying vegetation (Bertness and Ellison 1987) and cut bank erosion that may induce vegetation collapse (D'Alpaos et al. 2007; Hughes et al. 2009). However, we rarely found evidence of a wrack deposition during field work, and the effect of bank erosion is beyond the scope of this study. The point bars we investigated are characterized primarily by sedimentary processes that continuously create new potential space for the establishment of pioneer plants. Due to their very low surface elevation, the bars undergo submergence by sea water driven by semi-diurnal tidal flows along channels, as well as limited nutrient availability. These factors are perceived predominantly as chronic environmental stresses rather than abrupt, destructive disturbing forces. In short, we propose that there is little significant effect of disturbance in the creek system at the Skallingen salt marsh.

\section{Data acquisition in the field}

We selected 11 point bars across various tidal creeks on the Skallingen salt marsh (Fig. 2b). The point bars were carefully chosen based on several field reconnaissance trips across the marsh. In particular, we tried to select only those bars that looked representative of all bars at Skallingen, in terms of size, sinuosity, channel width, and depth (e.g., Fig. 2d, e). In each bar, two replicate 1 $\mathrm{m} \times 1 \mathrm{~m}$ square quadrats were established at the lower end of vegetation (Fig. 2c). Each quadrat was subdivided 
into 25 small grids of $0.2 \mathrm{~m} \times 0.2 \mathrm{~m}$, and in each of the grids, we recorded the presence of vascular plant species. Species nomenclature followed Tind (2003). Each quadrat was vertically divided into five classes, so the 5 grids $(0.2 \mathrm{~m} \times 0.2 \mathrm{~m})$ in a class represented the same height level. In each class, the frequency of each species varied from 0 to 5. Topographic surveys were conducted at the midpoint between the replicate quadrats using a differential Global Positioning System (Trimble R4 GPS Receiver and Trimble Recon ${ }^{\circ}$ Controller). The device produced errors in elevation less than $0.02 \mathrm{~m}$ at each point sampled.

\section{Data analysis}

Before estimating diversity and niche indices, a hierarchical cluster analysis was conducted to classify the selected point bars into ecologically meaningful groups. A combination of Sørensen's distance measure and flexible Beta $(\beta=-0.25)$ was used (McCune and Grace 2002). All samples were first relativized to make the observational units equitable in species abundance and to enhance the detection of broad compositional similarities among samples. After cluster analysis, we used indicator species analysis to quantitatively choose the optimum number of groups (Dufrene and Legendre 1997). Based on the final indicator values for each species that were calculated by multiplying its relative abundance and relative frequency by the group, the significance of the highest indicator value for a given species across groups was evaluated by 5000 runs of Monte Carlo tests. The resulting $p$ values were utilized as an objective criterion for pruning the cluster dendrogram. The step with the smallest average $p$ value was judged to be the most informative level in the dendrogram (McCune and Grace 2002).

In this research, we sought to address whether niche differentiation is required for species coexistence using two niche parameters: niche overlap and niche breadth. As these indices are associated with patterns of resource sharing among species, the first task should be to identify the major resource dimensions (e.g., light, water, and nutrients). However, this issue is regarded as one of the most challenging jobs in the study of niche theory and species coexistence (Mason et al. 2011). Furthermore, much of the published literature, even after reporting very high niche overlap along a certain niche axis, acknowledges that there still is a possibility that intensive competition and reduced niche overlap might be occurring along other dimensions (e.g., Colwell and Futuyma 1971; Mahdi et al. 1989; Gotelli and Entsminger 2011).

A number of factors can potentially control the spatial variability of physical conditions and vegetation in salt marshes, but the conventional paradigm suggests that tidal flooding, mediated by marsh elevation in relation to high water statistics, constitutes the fundamental factor that explains most other environmental variations (Pennings et al. 2005; Silvestri et al. 2005; Davy et al. 2011; Lee et al. 2018a, 2018b; Nam et al. 2018; Kim 2019). A corollary of this paradigm is that there is a single prominent and overriding stress gradient represented by surface elevation that governs the zonal patterns of physical variables and vegetation. This emphasis led Russell et al. (1985) to select elevation as the main niche dimension in their evaluation of the niche overlap hypothesis in two English salt marshes.

Following this example, we estimated niche overlap and niche breadth along the height dimension at each selected bar. This strategy is supported by our previous findings: Kim et al. (2012) performed intensive analyses on soil-plant-topography relationships across tidal creeks to demonstrate that soil nutrient variables (e.g., $\mathrm{N}, \mathrm{P}$, and $\mathrm{K}$ ) had a surprisingly minor influence on the spatial pattern of vegetation, whereas surface elevation was the primary determinant of both edaphic and floristic patterns. Of course, the overriding effects of elevation might be somewhat blurred when there is micro-scale heterogeneity in sediment properties, such as texture, hydraulic conductivity, and drainage conditions (Davy et al. 2011). However, this current research was concerned only with point bars that are characterized by extremely uniform sandy substrates. These sediments have been newly deposited with little time for significant compaction or for micro-scale differentiation of physical and chemical properties. Furthermore, Schoener (1974) argued that microhabitat is one of the three most important niche axes (the other two are diet and temporal activity) and that most differentiation should occur along microhabitat gradients. The microhabitat corresponds to different height classes in this study (Fig. 2c). Thus, strictly speaking, we are measuring the overlap of microhabitats with different elevations among species, not the degree of true resource sharing per se (see also Gotelli et al. 1997). However, as justified above, it is assumed that this height dimension will successfully represent the main resource axes that are present in the marsh.

At each bar, we set the lower end of vegetation as the reference point (Fig. 2c). Although these elevations may differ from one another in terms of their absolute values in $\mathrm{m}$ DNN (Danish Ordnance Zero), they are still the same in that they commonly represent the threshold condition at which pioneer plants are able to colonize. Some bars are expected to show the presence of plants even at extremely low sites, while other bars exhibit pioneer species only at their highest portions. In the former case, pioneers should experience highly frequent sea water inundation (i.e., extremely harsh conditions). In the latter, they are under more moderate conditions. Accordingly, we were able to examine how niche and diversity indices 
varied along a gradient from the highest to lowest stresses represented by surface elevation.

We were concerned with the different diversity indices of each quadrat because diversity often indicates the level of competitive effects and is crucial for evaluating the hypothesis of this study (Fig. 1). Diversity includes at least two different aspects of community structure: richness and evenness. Richness refers to the number of different species present in a community, and evenness indicates their relative abundance. As Scrosati and Heaven (2007) pointed out, there were two related issues with the use of diversity indexes in the ecological literature: (1) the interchangeable use of diversity and richness and (2) the lack of attention to and inclusion of evenness (Mackey and Currie 2001; Kimbro and Grosholz 2006). Recently, ecologists have recognized that these two issues should be resolved to better understand patterns of biodiversity (Bruno et al. 2003; Scrosati and Heaven 2007; Kim et al. 2013). In this research, we examined trends in both richness and evenness across different bars.

Richness $(S)$ was determined by simply counting the total number of species present in each quadrat. Then, we calculated the Shannon-Wiener (S-W) index $\left(H^{\prime}\right)$ to represent the level of species diversity in each quadrat:

$$
H^{\prime}=-\sum p_{i}\left(\ln p_{i}\right)
$$

where $p_{i}$ is the proportion of each species in each quadrat. We represented the evenness of each quadrat using Pielou's (1969) evenness index $\left(J^{\prime}\right)$ :

$$
J^{\prime}=H^{\prime} / H_{\text {max }}^{\prime}
$$

where $H^{\prime}{ }_{\max }$ is the maximum value of $\mathrm{S}-\mathrm{W}$ diversity, equal to $\ln (S)$. We evaluated the relationship between these three diversity indices and surface elevation using a simple regression analysis to examine whether there was an overall trend in species diversity along environmental stress gradients and, in particular, whether the highest diversity was observed with the intermediatelevel submergence stress. The diversity values estimated from the replicate quadrats were averaged before regression.

Finally, based on the frequency data in each height class (Fig. 2c), we estimated niche (i.e., microhabitat) overlap (O) using Pianka's (1973) formula:

$$
O_{i k}=O_{k i}=\frac{\sum_{j=1}^{j=n} p_{i j} p_{k j}}{\sqrt{\sum_{j=1}^{j=n} p_{i j}^{2} \sum_{j=1}^{j=n} p_{k j}^{2}}}
$$

where $O_{i k}$ and $O_{k i}$ are mutual habitat overlaps of species $i$ and $k$, respectively, $p_{i j}$ is the abundance of species $i$ in height class $j$, and $n$ is the number of classes into which the height has been divided. The index ranges from zero (no habitats used in common between two species) to one (complete overlap in habitat use). Niche (i.e., microhabitat) breadth $(B)$ was calculated for each species using Levins' (1968) equation:

$$
B_{i j}=\frac{1}{\sum_{j=1}^{j=n} p_{i j}^{2}}
$$

All calculations of overlaps and breadths were based on the proportional occurrences of species in each height class. Therefore, niche parameters were not influenced by differences in the absolute abundance of species among various point bars, and direct comparison of these parameters is appropriate. Species richness, evenness, and S-W diversity were regressed against niche overlap and niche breadth to evaluate the hypothesis of this research (Fig. 1).

\section{Results}

The surface elevation where plants started to grow (i.e., the lower end of vegetation) greatly differed among the 11 bars surveyed (Figs. 3 and 4). For example, the vertical difference in the lower limits of vegetation between bars 1 and 11 was $0.23 \mathrm{~m}$.

We identified seven vascular plant species: Spartina anglica C. E. Hubb, Salicornia herbacea L., Suaeda maritima L., Puccinellia maritima (Hudson) Parl., Aster tripolium L., Limonium vulgare Mill. and L. humile Mill., and Atriplex portulacoides L. The cluster analysis classified the point bars into four groups:

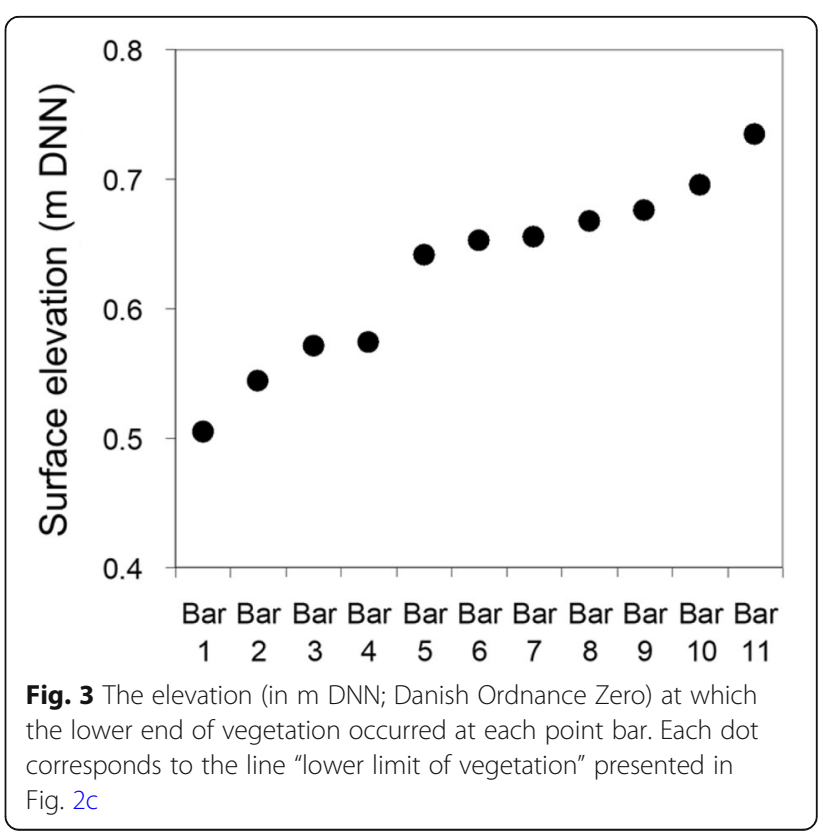



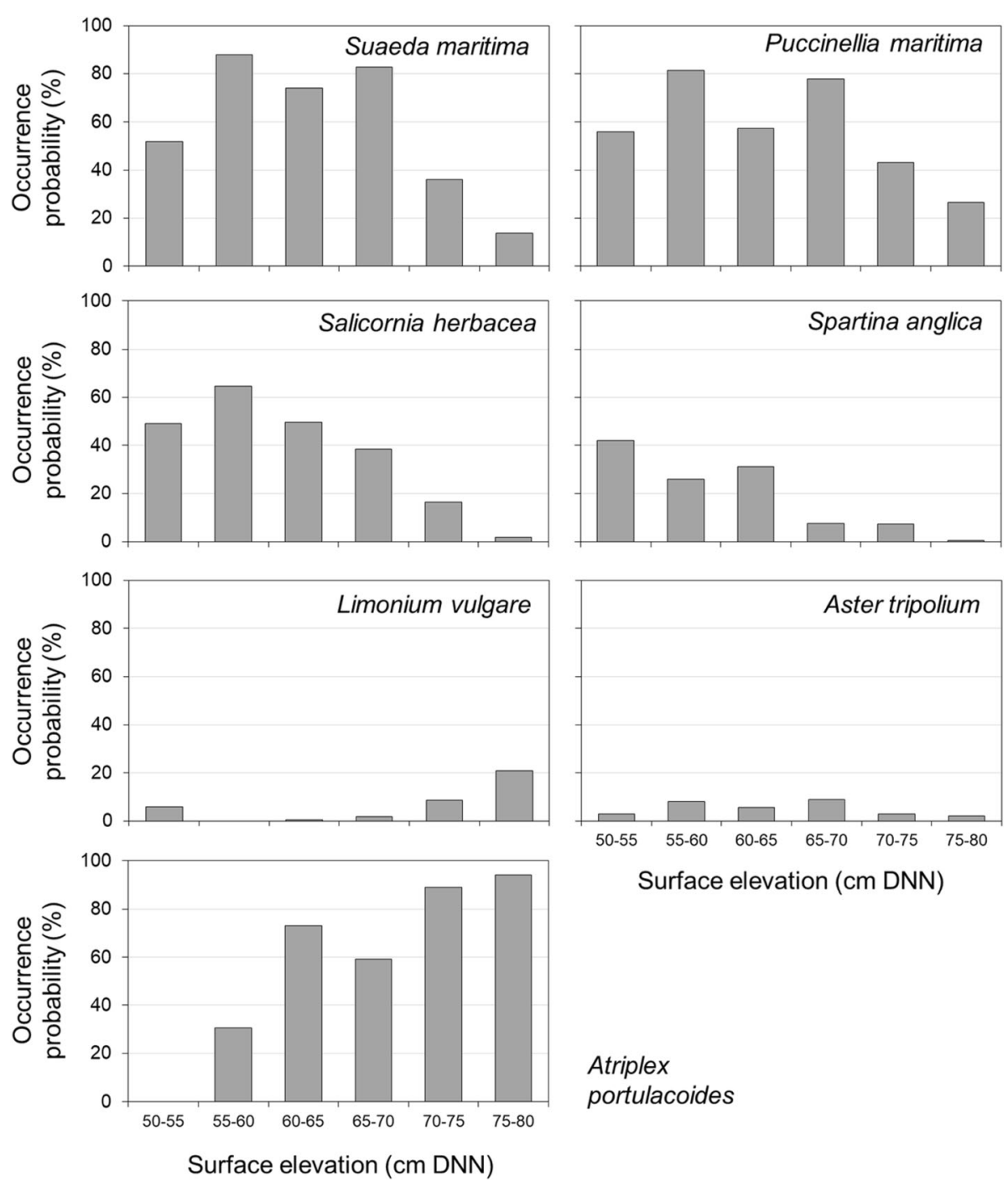

Surface elevation (cm DNN)

\section{Atriplex}

portulacoides

Fig. 4 The occurrence probability (\%) of each plant species along the gradient of surface elevation (DNN, Danish Ordnance Zero)

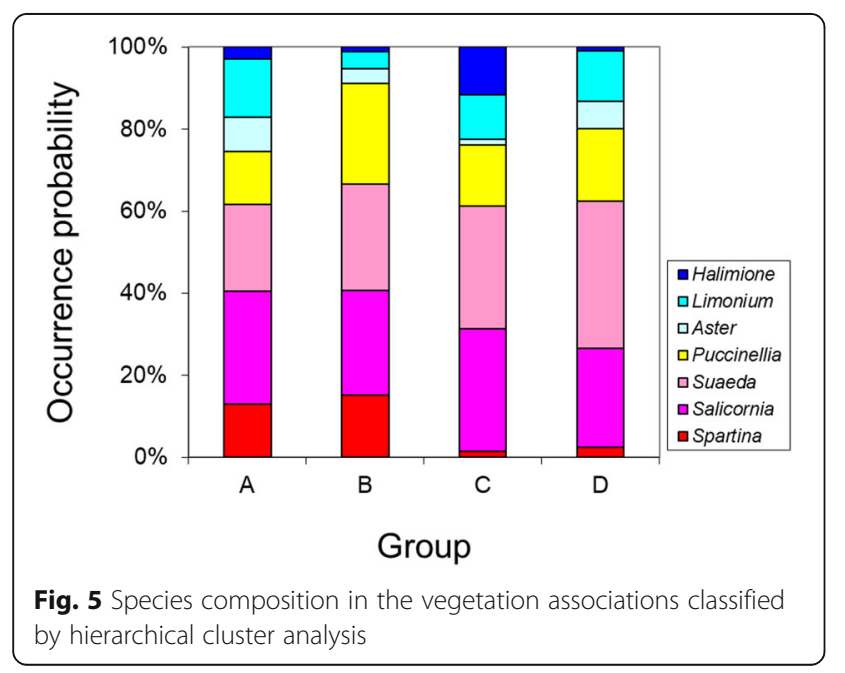

bars 1, 2, and 3 belonged to group A. Bar 4 comprised group B. Group C contained bars 5, 6, 7, and 8 , and the other bars were classified into group D. The four groups had the same species richness (i.e., seven); however, there were substantial compositional variations across the groups (Fig. 5). In particular, Spartina showed some degree of occurrence probability (>10\%) in groups A and B, but it was extremely minor in groups with higher surface elevations (see Fig. 3).

S-W diversity, species richness, and evenness exhibited strikingly linear and significant relationships with bar surface elevation, niche overlap, and niche breadth (Fig. 6). The diversity indices decreased with increasing elevation, whereas they were positively correlated with the niche parameters. The niche 

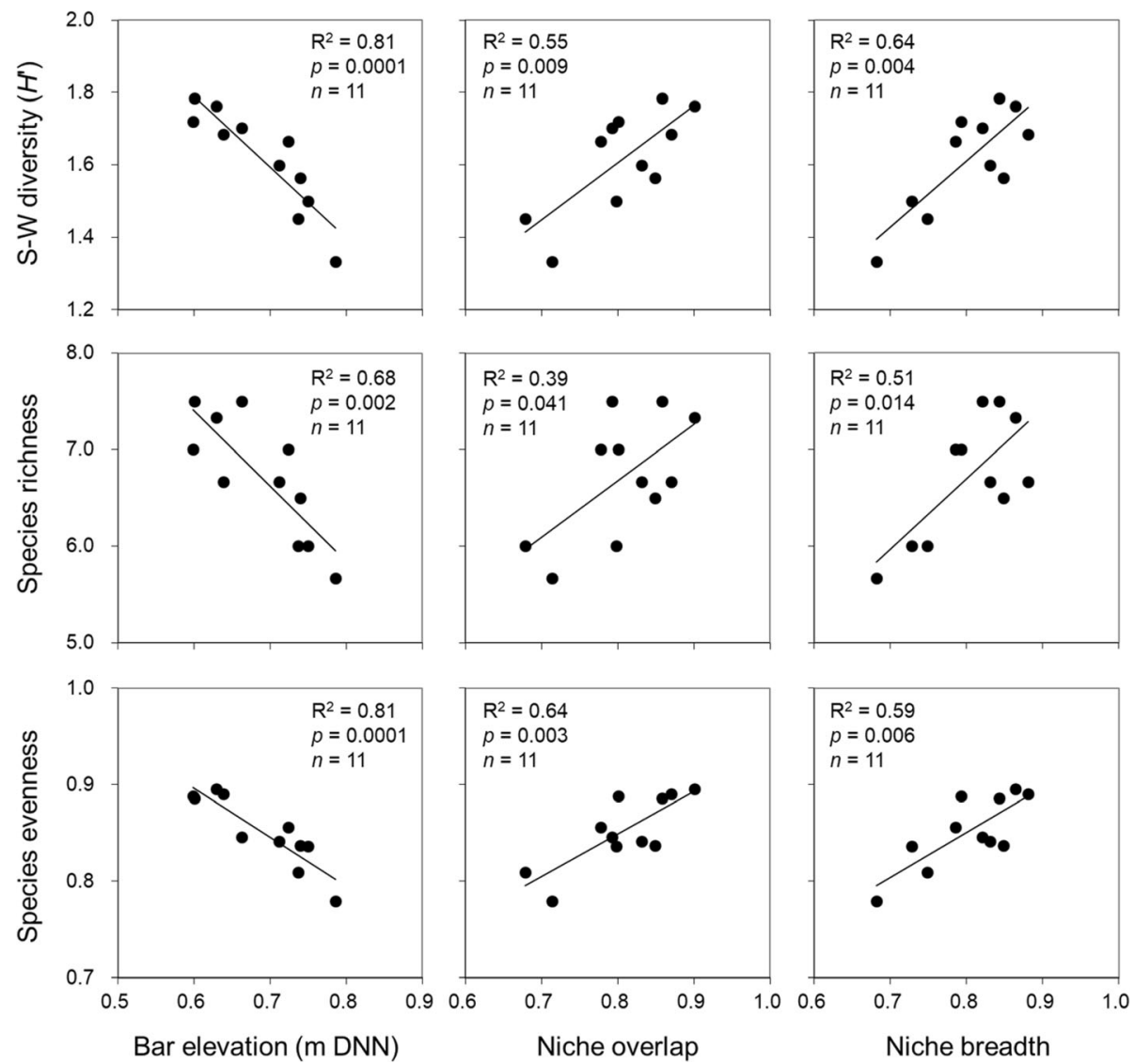

Fig. 6 Diversity indices predicted by bar elevation (in m DNN; Danish Ordnance Zero), niche overlap, and niche breadth

parameters significantly decreased with increasing bar surface elevation (Fig. 7).

\section{Discussion}

\section{Stress and diversity}

It is noteworthy that, although the pioneer zones of all selected bars were undoubtedly considered very stressful, there were substantial variations in the level of harshness among the zones. These bars, despite having undergone the same hydrogeomorphic processes (i.e., deposition of coarse sediments; Kim et al. 2010, 2013) and possessing similarly low surface elevations (Kim et al. 2012), were characterized by greatly different elevations at which pioneer plants start to grow (Fig. 3). The elevation difference in the lower ends of vegetation between bars 1 and 11 (i.e., $0.23 \mathrm{~m}$ ) is considered remarkably large in ordinary salt marshes, given that soil properties and species composition respond significantly to even a few centimeters of topographic and consequently hydrologic changes (Adam 1990; Kim et al. 2012). The results of this study indicate that the pioneer zones of the selected bars are located at different surface elevations, encompassing extremely harsh and slightly less harsh conditions.
Therefore, the creek bars of the Skallingen salt marsh are excellent laboratories for evaluating the original research questions of this study, concerning mechanisms of species coexistence along the gradient of environmental harshness (see "Hypothesis" section).

We consider that a definable diversity pattern exists along the stress gradient represented by surface elevation, and that high-level biodiversity is related to physical harshness in the study area. The linear increases of diversity indices toward the lower end of elevation (left column of Fig. 6) imply that strong harshness might be a driving force of species coexistence and high diversity. Therefore, it is plausible that the ecology of the Skallingen bar system does not fit into the traditional notion of environmental stress models which posit that an intermediate-level stress can promote species coexistence and diversity (see "Theory III: coexistence along environmental stress gradients" section). In particular, the high evenness under harsh conditions needs to be examined to fully understand the possible mechanisms of species coexistence in low-elevation bars.

It has long been thought that environmental harshness drives low species evenness. From diverse stream 

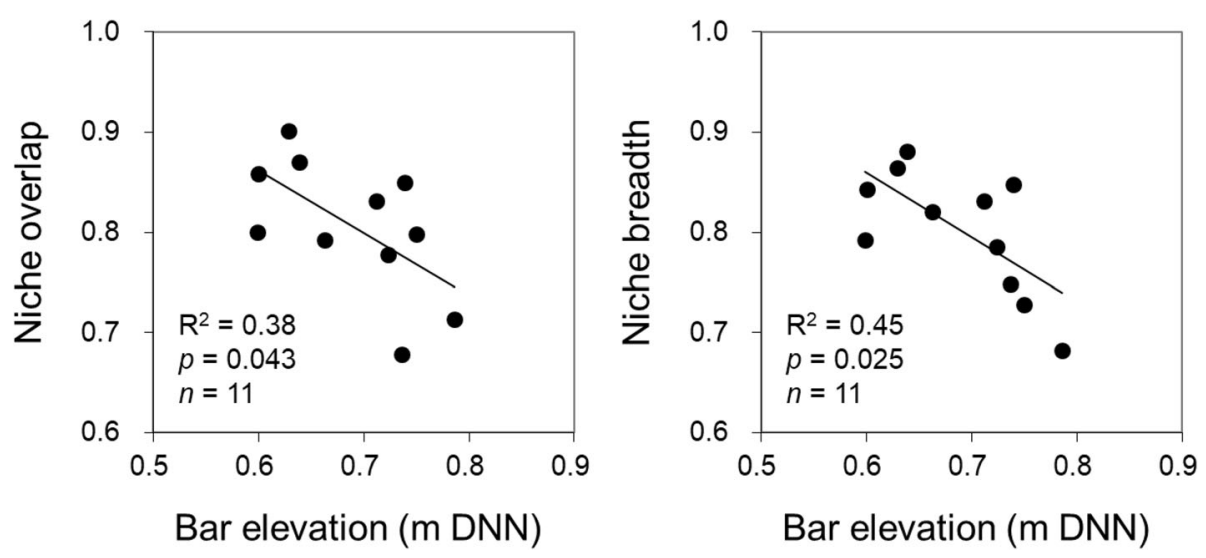

Fig. 7 Niche indices predicted by bar elevation (in m DNN; Danish Ordnance Zero)

systems in a California watershed, Bendix (1997) found that large flood events removed most of a given species from a site, thereby reducing evenness. In a similar context, Scrosati and Heaven (2007) considered that, under the high physical stress of rocky intertidal seashores, evenness should become low because only a small fraction of all the species present would tolerate the harsh conditions, with the remaining few species being scarce. However, the patterns we identified at the point bars at Skallingen are in apparent disagreement with these previous findings.

It should be noted that, in previous research, the harsh conditions often refer to, or at least include, disturbances that cause sudden mortality in a given system, be it partial or complete. However, the stressful factors in the sheltered backbarrier marsh at Skallingen are explained predominantly by regular submergence (Study area), and these stresses are not necessarily lethal to pioneer plant species surveyed. In Skallingen, we found that high-level stress caused evenness to increase. This accords well with the ideas of Tilman (1985) and Chesson and Huntly (1997) introduced in the "Theory III: coexistence along environmental stress gradients" section.

The seven species surveyed in this research are survivors of stressful physical filters that are primarily imposed by seawater inundation. These species are generally adapted to the ambient environmental stresses (Sánchez et al. 1996; Costa et al. 2003), and therefore, they are potentially capable of colonizing any site within a bar. At the lowest elevation near $0.6 \mathrm{~m} \mathrm{DNN}$, these plants seem to facilitate each other, resulting in high species richness and evenness (Fig. 6), in accordance with the stress gradient hypothesis (see "Theory III: coexistence along environmental stress gradients" section). However, species richness clearly decreased as the bar elevation increased, a pattern most likely induced by competitive exclusion (Kim 2019). Due to environmental harshness, there was no opportunity for a dominant species that monopolized available resources to reduce both evenness and diversity. In a similar context, chronic stresses are known to suppress the dominance of a particular (set of) species, and retard competitive exclusion, thereby maintaining high species richness (Peet et al. 1983; Shmida and Ellner 1984). At Skallingen, we empirically identified a more even distribution of different species in more stressful bars than in slightly higherelevation bars. Of course, the results might vary if mid to late-successional species had been considered. For example, as surface elevation increases toward channel levees, plant species having greater competitive abilities will survive, reducing diversity and niche parameters (Kim et al. 2013).

\section{Diversity and niche parameters}

The basic question of this study was whether high species diversity was maintained by niche differentiation that indicated low niche overlap. At the Skallingen salt marsh bar system, we found a surprising pattern where both niche overlap and breadth were high even in the case of high species diversity (middle and right columns of Fig. 6). This positive relationship conflicts with the traditional niche theory (Theory I: coexistence maintained by niche differentiation). The current results seem to support the theory of competitive combining ability or balanced competition (Aarssen 1983, 1984; Zobel 1992; Theory II: coexistence without niche differentiation). The finding that diversity indices, niche overlap, and niche breadth were all high at highly stressful sites advocates a possibility that different species tend to possess similar competitive abilities, rather than avoiding competition through niche differentiation. Moreover, species at lower elevations possibly enhance the relative fitness of other species by limiting their own fitness. This implies a strong effect from the equalizing mechanism that reduces differences in relative fitness among species (Chesson 2013; Theory V: coexistence under non- 


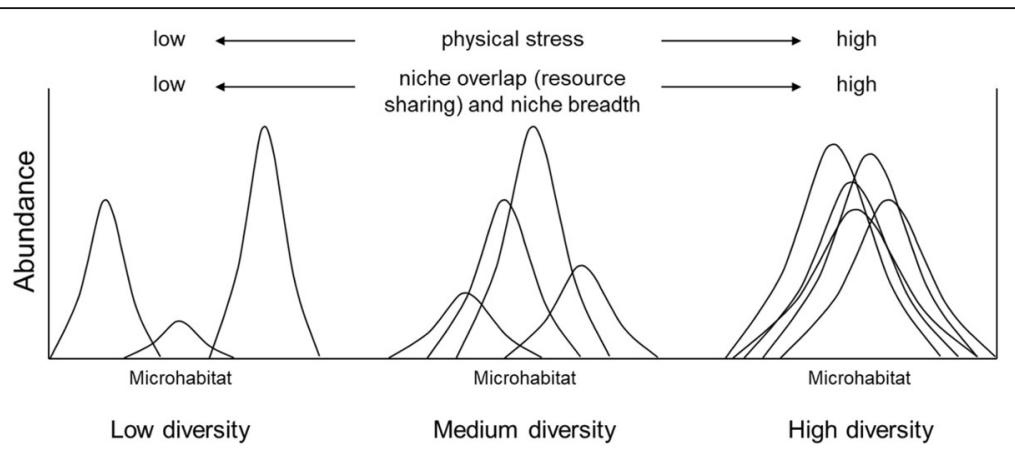

Fig. 8 Observed patterns in the level of environmental stress and niche characteristics along a gradient of microhabitat (i.e., surface elevation) at different levels of species diversity, Skallingen, Denmark

equilibrium versus equilibrium conditions). In short, balanced competitive ability and equalizing fitness differences appear to be key to the success of each pioneer species, and hence, the observed high evenness. Finally, based on the decreasing niche indices with increasing elevation (Fig. 7), we posit that the relative importance of niche-based deterministic and stochastic mechanisms varies along the stress gradient in this study: At lowlying, more stressful sites, stochastic processes seem to be dominant, whereas deterministic niche differentiation likely operates at higher, less stressful sites (Kim 2019).

These observed ecological patterns and discussions led us to revise the original hypothesis and develop an alternative conceptual model for the study marsh (Fig. 8). In the past, one limitation of the concepts of competitive combining ability and balanced competition has been a lack of empirical data acquired by observational approaches in the field. While the proposed new model has been developed from a single system, we believe that it still has the potential to support these underrepresented classical theories (Aarssen 1983, 1989; Zobel 1992). More number of such studies should be conducted in different ecological systems.

\section{Conclusions}

In this paper, we have shown that different diversity indices consistently had negative relationships with surface elevation and positive relationships with niche overlap and niche breadth. These two niche metrics linearly decreased with increasing elevation. These results were considered to reflect the importance of an equalizing mechanism that reduced differences in relative fitness among species in the study marsh.

In coastal environments, the potential impacts of recent climate change on ecological patterns and processes have been a central issue, not only for scientists but also for coastal zone managers, policy makers, and the general public (Feagin et al. 2010; Kirwan et al. 2010). The impacts are often perceived as profound alterations of surrounding physical conditions, which can be interpreted as increasing the effects of harshness on inhabiting species. For example, increased frequency, duration, and magnitude of waterlogging driven by recent sea-level anomalies are the main foci of a number of initiatives that the USA and European Union (e.g., Western Climate Initiative; Natura2000 Network) seek to include in their integrated coastal zone management plans (EEA 2006). We believe that understanding the mechanisms of species coexistence and the resultant biodiversity under highly stressful physical conditions will be increasingly required as a springboard for fully understanding community structure and function and for developing appropriate conservation strategies. However, because of the limited current knowledge on the ecology of stressful systems, any prediction as to the mode of species interactions and patterns of coexistence under future climate change and altered stress regimes would be difficult. We propose that more researchers investigate the ecology of very harsh systems in various types of ecosystems.

\section{Acknowledgements \\ The logistical support of Professor Jesper Bartholdy is greatly appreciated.}

\section{Authors' contributions}

DK conceived the research and conducted field and lab experiments. Both DK and SO reviewed previous studies and wrote the manuscript. The authors read and approved the final manuscript.

\section{Funding}

This study was supported by the National Science Foundation (\#0825753) and the National Research Foundation of Korea (NRF-2017R1C1B5076922).

\section{Availability of data and materials}

The data sets analyzed in the present paper are available upon request from the corresponding author.

Ethics approval and consent to participate

Not applicable.

Consent for publication

Not applicable.

Competing interests

The authors declare that they have no competing interests. 
Received: 17 May 2020 Accepted: 22 June 2020

\section{Published online: 29 July 2020}

\section{References}

Aarssen LW. Ecological combining ability and competitive combining ability in plants: toward a general evolutionary theory of coexistence in systems of competition. Am Nat. 1983;122:707-31.

Aarssen LW. On the distinction between niche and competitive ability: implications for coexistence theory. Acta Biotheor. 1984;33:67-83.

Aarssen LW. Competitive ability and species coexistence: a "plant's-eye" view. Oikos. 1989;56:386.

Aarssen LW. Causes and consequences of variation in competitive ability in plant communities. J Veg Sci. 1992;3:165-74.

Abrams P. The theory of limiting similarity. Annu Rev Ecol Syst. 1983;14:359-76.

Adam P. Saltmarsh ecology. Cambridge: Cambridge University Press; 1990.

Adler PB, HilleRisLambers J, Levine JM. A niche for neutrality. Ecol Lett. 2007;10: 95-104.

Ågren Gl, Fagerström T, Agren Gl, Fagerstrom T. Limiting dissimilarity in plants: randomness prevents exclusion of species with similar competitive abilities. Oikos. 1984:43:369.

Alonso D, Etienne R, McKane A. The merits of neutral theory. Trends Ecol Evol. 2006;21:451-7.

Anderegg WRL, Kane JM, Anderegg LDL. Consequences of widespread tree mortality triggered by drought and temperature stress. Nat Clim Chang. 2013;3:30-6.

Araújo MB, Guisan A. Five (or so) challenges for species distribution modelling. J Biogeogr. 2006;33:1677-88.

Araújo MB, Pearson RG. Equilibrium of species' distributions with climate. Ecography. 2005;28:693-5.

Barabás G, D'Andrea R, Stump SM. Chesson's coexistence theory. Ecol Monogr. 2018:88:277-303.

Bartholdy J, Aagaard T. Storm surge effects on a back-barrier tidal flat of the Danish Wadden Sea. Geo-Marine Lett. 2001;20:133-41.

Bell G. The distribution of abundance in neutral communities. Am Nat. 2000;155: 606-17.

Bendix J. Flood disturbance and the distribution of riparian species diversity. Geogr Rev. 1997;87:468.

Bertness MD, Callaway R. Positive interactions in communities. Trends Ecol Evol. 1994;9:191-3.

Bertness MD, Ellison AM. Determinants of pattern in a New England salt marsh plant community. Ecol Monogr. 1987;57:129-47.

Bertness MD, Gaines SD, Hay ME. Marine community ecology. Sunderland: Sinauer Associates, Inc.; 2001.

Bertness MD, Shumway SW. Competition and facilitation in marsh plants. Am Nat. 1993;142:718-24.

Black AJ, McKane AJ. Stochastic formulation of ecological models and their applications. Trends Ecol Evol. 2012;27:337-45.

Brown WL, Wilson EO. Character displacement. Syst Zool. 1956;5:49-64.

Bruno JF, Stachowicz JJ, Bertness MD. Inclusion of facilitation into ecological theory. Trends Ecol Evol. 2003;18:119-25.

Callaway RM, Brooker RW, Choler P, Kikvidze Z, Lortie CJ, Michalet R, et al. Positive interactions among alpine plants increase with stress. Nature. 2002;417:844-8.

Chase JM. Drought mediates the importance of stochastic community assembly. Proc Natl Acad Sci U S A. 2007;104:17430-4.

Chase JM. Stochastic community assembly causes higher biodiversity in more productive environments. Science. 2010;328:1388-91.

Chase JM, Leibold MA. Ecological niches. Chicago: University of Chicago Press; 2003.

Chase JM, Myers JA. Disentangling the importance of ecological niches from stochastic processes across scales. Philos Trans R Soc B Biol Sci. 2011;366: 2351-63.

Chave J. Neutral theory and community ecology. Ecol Lett. 2004;7:241-53.

Chesson P. Mechanisms of maintenance of species diversity. Annu Rev Ecol Syst. 2000;31:343-66.

Chesson P. Species competition and predation. In: Leemans R, editor. Ecological systems. New York: Springer; 2013. p. 223-56.

Chesson P, Huntly N. The roles of harsh and fluctuating conditions in the dynamics of ecological communities. Am Nat. 1997;150:519-53.

Chisholm RA, Pacala SW. Niche and neutral models predict asymptotically equivalent species abundance distributions in high-diversity ecological communities. Proc Natl Acad Sci U S A. 2010;107:15821-5.
Cho H, Marrs RH, Alday JG, Cho K-H. Vertical and longitudinal variations in plant communities of drawdown zone of a monsoonal riverine reservoir in South Korea. J Ecol Environ. 2019;43:27. https://doi.org/10.1186/s41610-019-0123-6. Clark JS. Beyond neutral science. Trends Ecol Evol. 2009;24:8-15.

Clark JS. The coherence problem with the unified neutral theory of biodiversity. Trends Ecol Evol. 2012;27:198-202.

Colwell RK, Futuyma DJ. On the measurement of niche breadth and overlap. Ecology. 1971;52:567-76.

Connell JH. Diversity in tropical rain forests and coral reefs. Science. 1978;199: 1302-10.

Costa CSB, Marangoni JC, Azevedo AMG. Plant zonation in irregularly flooded salt marshes: relative importance of stress tolerance and biological interactions. J Ecol. 2003;91:951-65.

D'Alpaos A, Lanzoni S, Marani M, Rinaldo A. Landscape evolution in tidal embayments: modeling the interplay of erosion, sedimentation, and vegetation dynamics. J Geophys Res. 2007;112:F1.

D'Andrea R, Ostling A. Challenges in linking trait patterns to niche differentiation. Oikos. 2016;125:1369-85.

Darwin C. On the origin of species. London: Murray; 1859.

Davy AJ, Brown MJH, Mossman HL, Grant A. Colonization of a newly developing salt marsh: disentangling independent effects of elevation and redox potential on halophytes. J Ecol. 2011;99:1350-7.

Diamond JM. Assembly of species communities. In: Cody ML, Diamond JM, editors. Ecology and evolution of communities; 1975. p. 342-444.

Dufrene M, Legendre P. Species assemblages and indicator species: the need for a flexible asymmetrical approach. Ecol Monogr. 1997;67:345.

EEA (European Economic Area). The changing faces of Europe's coastal areas, EEA Report No. 6/2006. Copenhagen: European Environment Agency; 2006.

Ellner SP, Snyder RE, Adler PB, Hooker G. An expanded modern coexistence theory for empirical applications. Ecol Lett. 2019;22:3-18.

Feagin RA, Martinez ML, Mendoza-Gonzalez G, Costanza R. Salt marsh zonal migration and ecosystem service change in response to global sea level rise: a case study from an urban region. Ecol Soc. 2010;15:art14.

Finke DL, Snyder WE. Niche partitioning increases resource exploitation by diverse communities. Science. 2008:321:1488-90.

FitzGerald DM, Fenster MS, Argow BA, Buynevich IV. Coastal impacts due to sealevel rise. Annu Rev Earth Planet Sci. 2008:36:601-47.

Fox JW. The intermediate disturbance hypothesis should be abandoned. Trends Ecol Evol. 2013;28:86-92.

Fridley JD, Grime JP, Bilton M. Genetic identity of interspecific neighbors mediates plant responses to competition and environmental variation in a species-rich grassland. J Ecol. 2007;95:908-15.

Fukami T. Historical contingency in community assembly: integrating niches, species pools, and priority effects. Annu Rev Ecol Evol Syst. 2015;46:1-23.

Gause GF. The struggle for existence. New York: Hafner; 1934.

Gotelli NJ, Buckley NJ, Wiens JA. Co-occurrence of Australian land birds: Diamond's assembly rules revisited. Oikos. 1997;80:311-24.

Gotelli NJ, Entsminger GL. EcoSim: null modeling software for ecology (version 7. 0). Jericho: Acquired Intelligence Inc. and Kesey-Bear; 2011.

Gravel D, Bell T, Barbera C, Bouvier T, Pommier T, Venail P, et al. Experimental niche evolution alters the strength of the diversity-productivity relationship. Nature. 2011:469:89-92.

Gravel D, Canham CD, Beaudet M, Messier C. Reconciling niche and neutrality: the continuum hypothesis. Ecol Lett. 2006;9:399-409.

Grime JP. Plant strategies, vegetation processes, and ecosystem properties. 2nd ed. Hoboken: Wiley; 2001.

Grubb PJ. The maintenance of species-richness in plant communities: the importance of the regeneration niche. Biol Rev. 1977;52:107-45.

Guo H, Więski K, Lan Z, Pennings SC. Relative importance of deterministic processes on structuring marsh plant communities varies across an abiotic gradient. Oikos. 2014;123:173-8.

Hart SP, Marshall DJ. Environmental stress, facilitation, competition, and coexistence. Ecology. 2013;94:2719-31.

$\mathrm{He} \mathrm{Q}$, Berness MD. Extreme stresses, niches, and positive species interactions along stress gradients. Ecology. 2014;95:1437-43.

HilleRisLambers J, Adler PB, Harpole WS, Levine JM, Mayfield MM. Rethinking community assembly through the lens of coexistence theory. Annu Rev Ecol Evol Syst. 2012;43:227-48.

Holmgren M, Scheffer M. Strong facilitation in mild environments: the stress gradient hypothesis revisited. J Ecol. 2010;98:1269-75. 
Holmgren M, Stapp P, Dickman CR, Gracia C, Graham S, Gutiérrez JR, et al. Extreme climatic events shape arid and semiarid ecosystems. Front Ecol Environ. 2006:4:87-95

Holyoak M, Loreau M. Reconciling empirical ecology with neutral community models. Ecology. 2006;87:1370-7.

Hooper DU, Chapin FS, Ewel JJ, Hector A, Inchausti P, Lavorel S, et al. Effects of biodiversity on ecosystem functioning: a consensus of current knowledge. Ecol Monogr. 2005;75:3-35.

Hubbell SP. The unified neutral theory of biodiversity and biogeography. Princeton University Press: Princeton; 2001

Hughes TP, Rodrigues MJ, Bellwood DR, Ceccarelli D, Hoegh-Guldberg O, McCook $L$, et al. Phase shifts, herbivory, and the resilience of coral reefs to climate change. Curr Biol. 2007;17:360-5.

Hughes ZJ, FitzGerald DM, Wilson CA, Pennings SC, Więski K, Mahadevan A. Rapid headward erosion of marsh creeks in response to relative sea level rise. Geophys Res Lett. 2009;36:L03602.

Huston M. A general hypothesis of species diversity. Am Nat. 1979;113:81-101.

Hutchinson GE. Homage to Santa Rosalia or why are there so many kinds of animals? Am Nat. 1959:93:145-59.

Ives AR, Carpenter SR. Stability and diversity of ecosystems. Science. 2007;317:5862.

Jabot F, Chave J. Analyzing tropical forest tree species abundance distributions using a nonneutral model and through approximate Bayesian inference. Am Nat. 2011;178:E37-47.

Jeraldo P, Sipos M, Chia N, Brulc JM, Dhillon AS, Konkel ME, et al. Quantification of the relative roles of niche and neutral processes in structuring gastrointestinal microbiomes. Proc Natl Acad Sci U S A. 2012;109:9692-8.

Jiménez MA, Jaksic FM, Armesto JJ, Gaxiola A, Meserve PL, Kelt DA, et al. Extreme climatic events change the dynamics and invasibility of semi-arid annual plant communities. Ecol Lett. 2011:14:1227-35.

Jung SH, Kim AR, Lim BS, Seol JW, Lee CS. Spatial distribution of vegetation along the environmental gradient on the coastal cliff and plateau of Janggi peninsula (Homigot), southeastern Korea. J Ecol Environ. 2019;43:14. https:// doi.org/10.1186/s41610-019-0110-y.

Kalyuzhny M, Kadmon R, Shnerb NM. A neutral theory with environmental stochasticity explains static and dynamic properties of ecological communities. Ecol Lett. 2015;18:572-80.

Kelly $A E$, Goulden ML. Rapid shifts in plant distribution with recent climate change. Proc Natl Acad Sci U S A. 2008;105:11823-6.

Kim D. Biogeomorphic feedbacks drive dynamics of vegetation-landform complex in a coastal riparian system. Ecosphere. 2012;3:art74.

Kim D. Rates of vegetation dynamics along elevation gradients in a backbarrier salt marsh of the Danish Wadden Sea. Estuar Coasts. 2014;37:610-20.

Kim D. Modeling spatial and temporal dynamics of plant species richness across tidal creeks in a temperate salt marsh. Ecol Indic. 2018;93:188-95.

Kim D. Selection of scale can reverse the importance of stochastic controls on community assembly. Phys Geogr. 2019:40:111-26.

Kim D, Bartholdy J, Jung S, Cairns DM. Salt marshes as potential indicators of global climate change. Geogr Compass. 2011b;5:219-36.

Kim D, Cairns DM, Bartholdy J. Environmental controls on multiscale spatial patterns of salt marsh vegetation. Phys Geogr. 2010;31:58-78.

Kim D, Cairns DM, Bartholdy J. Wind-driven sea-level variation influences dynamics of salt marsh vegetation. Ann Assoc Am Geogr. 2011a;101:231-48.

Kim D, Cairns DM, Bartholdy J. Tidal creek morphology and sediment type influence spatial trends in salt marsh vegetation. Prof Geogr. 2013:65:544-60.

Kim D, Cairns DM, Bartholdy J, Morgan CLS. Scale-dependent correspondence of floristic and edaphic gradients across salt marsh creeks. Ann Am Assoc Geogr. 2012;102:276-94

Kimbro DL, Grosholz ED. Disturbance influences oyster community richness and evenness, but not diversity. Ecology. 2006;87:2378-88.

Kirwan ML, Guntenspergen GR, D'Alpaos A, Morris JT, Mudd SM, Temmerman S. Limits on the adaptability of coastal marshes to rising sea level. Geophys Res Lett. 2010;37:L23401.

Lee EH, Lee BE, Kim JG. Effects of water levels and soil nutrients on the growth of Iris laevigata seedlings. J Ecol Environ. 2018a;42:5. https://doi.org/10.1186/ s41610-018-0065-4

Lee SH, Lee J-S, Kim J-W. Relationship between halophyte distribution and soil environmental factors in the west coast of South Korea. J Ecol Environ. 2018b;42:2. https://doi.org/10.1186/s41610-017-0062-z.

Leibold MA, McPeek MA. Coexistence of the niche and neutral perspectives in community ecology. Ecology. 2006;87:1399-410.
Lepori F, Malmqvist B. Deterministic control on community assembly peaks at intermediate levels of disturbance. Oikos. 2009:118:471-9.

Letten AD, Ke P-J, Fukami T. Linking modern coexistence theory and contemporary niche theory. Ecol Monogr. 2017;87:161-77.

Levins R. Evolution in changing environments: some theoretical explorations. Princeton: Princeton University Press; 1968.

Locke A. Factors influencing community structure along stress gradients: zooplankton responses to acidification. Ecology. 1992;73:903-9.

MacArthur R, Levins R. The limiting similarity, convergence, and divergence of coexisting species. Am Nat. 1967;101:377-85.

MacArthur RH. Geographical ecology. New York: Harper \& Row; 1972.

Mackey RL, Currie DJ. The diversity-disturbance relationship: is it generally strong and peaked? Ecology. 2001;82:3479-92.

Maestre FT, Callaway RM, Valladares F, Lortie CJ. Refining the stress-gradient hypothesis for competition and facilitation in plant communities. J Ecol. 2009;97:199-205

Maestre FT, Cortina J. Do positive interactions increase with abiotic stress? A test from a semi-arid steppe. P Roy Soc B-Biol Sci. 2004;271:S331-3.

Mahdi A, Law R, Willis AJ. Large niche overlaps among coexisting plant species in a limestone grassland community. J Ecol. 1989;77:386.

Mason NWH, de Bello F, Doležal J, Lepš J. Niche overlap reveals the effects of competition, disturbance and contrasting assembly processes in experimental grassland communities. J Ecol. 2011:99:788-96.

Matthews TJ, Whittaker RJ. Neutral theory and the species abundance distribution: recent developments and prospects for unifying niche and neutral perspectives. Ecol Evol. 2014;4:2263-77.

May RM, MacArthur RH. Niche overlap as a function of environmental variability. Proc Natl Acad Sci U S A. 1972:695:1109-13.

McCann KS. The diversity-stability debate. Nature. 2000;405:228-33.

McCune B, Grace JB. Analysis of ecological communities. In: MjM software design: Gleneden Beach; 2002.

McGill BJ, Maurer BA, Weiser MD. Empirical evaluation of neutral theory. Ecology. 2006:87:1411-23

Menge BA, Sutherland JP. Community regulation: variation in disturbance, competition, and predation in relation to environmental stress and recruitment. Am Nat. 1987:130:730-57.

Morris JT, Sundareshwar PV, Nietch CT, Kjerfve B, Cahoon DR. Responses of coastal wetlands to rising sea level. Ecology. 2002:83:2869-77.

Mougi A, Kondoh M. Diversity of interaction types and ecological community stability. Science. 2012;337:349-51.

Munoz F, Huneman P. From the neutral theory to a comprehensive and multiscale theory of ecological equivalence. Q Rev Biol. 2016;91:321-42.

Mutshinda CM, O'Hara RB. Integrating the niche and neutral perspectives on community structure and dynamics. Oecologia. 2011;166:241-51.

Nam BE, Hong MG, Park HJ, Kim JG. Soil factors determining the distribution of Phragmites australis and Phacelurus latifolius in upper tidal zone. J Ecol Environ. 2018:42:25. https://doi.org/10.1186/s41610-018-0086-z.

Nicholls R, Cazenave A. Sea-level rise and its impact on coastal zones. Science. 2010;328:1517-20.

Odum EP. Trends expected in stressed ecosystems. Bioscience. 1985;35:419-22.

Palmer MW. Variation in species richness: towards a unification of hypotheses. Folia Geobot Phytotaxon. 1994;29:511-30.

Peet RK, Glenn-Lewin DC, Wolf JW. Prediction of man's impact on plant species diversity. In: Holzner W, Werger MJA, Ikusima I, editors. A challenge for vegetation science. Junk: The Hague; 1983. p. 41-54.

Pennings SC, Grant M-B, Bertness MD. Plant zonation in low-latitude salt marshes: disentangling the roles of flooding, salinity and competition. J Ecol. 2005;93: 159-67.

Pianka ER. The structure of lizard communities. Annu Rev Ecol Syst. 1973:4:53-74.

Pianka ER. Niche overlap and diffuse competition. Proc Natl Acad Sci U S A. 1974; 71:2141-5.

Pickett STA. Non-equilibrium coexistence of plants. Bull Torrey Bot Club. 1980;107: 238-48.

Pielou EC. An Introduction to mathematical ecology. New York: WileyInterscience; 1969.

Pigolotti S, Cencini M. Species abundances and lifetimes: from neutral to nichestabilized communities. J Theor Biol. 2013;338:1-8.

Pocheville A. The ecological niche: history and recent controversies. In: Heams T, Huneman P, Lecointre G, Silberstein M, editors. Handbook of evolutionary thinking in the sciences. Heidelberg: Springer Netherlands; 2015. p. 547-86. 
Pos E, Guevara JE, Molino J-F, Sabatier D, Bánki OS, Pitman NCA, et al. Scaling issues of neutral theory reveal violations of ecological equivalence for dominant Amazonian tree species. Ecol Lett. 2019;22:1072-82.

Purves DW, Turnbull LA. Different but equal: the implausible assumption at the heart of neutral theory. J Anim Ecol. 2010;79:1215-25.

Rosindell J, Hubbell SP, Etienne RS. The unified neutral theory of biodiversity and biogeography at age ten. Trends Ecol Evol. 2011;26:340-8.

Rosindell J, Hubbell SP, He F, Harmon LJ, Etienne RS. The case for ecological neutral theory. Trends Ecol Evol. 2012;27:203-8.

Russell PJ, Flowers TJ, Hutchings MJ. Comparison of niche breadths and overlaps of halophytes on salt marshes of differing diversity. Vegetatio. 1985;61:171-8.

Sallenger AH, Doran KS, Howd PA. Hotspot of accelerated sea-level rise on the Atlantic coast of North America. Nat Clim Chang. 2012;2:884-8.

Sánchez JM, Izco J, Medrano M. Relationships between vegetation zonation and altitude in a salt-marsh system in northwest Spain. J Veg Sci. 1996;7:695-702.

Scheffer M, van Nes EH, Vergnon R. Toward a unifying theory of biodiversity. Proc Natl Acad Sci U S A. 2018;115:639-41.

Schoener T. Resource partitioning in ecological communities. Science. 1974;185: 27-39.

Scrosati R, Heaven C. Spatial trends in community richness, diversity, and evenness across rocky intertidal environmental stress gradients in eastern Canada. Mar Ecol Prog Ser. 2007:342:1-14.

Seager R, Ting M, Held I, Kushnir Y, Lu J, Vecchi G, et al. Model projections of an imminent transition to a more arid climate in southwestern North America. Science. 2007:316:1181-4.

Shmida A, Ellner S. Coexistence of plant species with similar niches. Vegetatio. 1984;58:29-55

Siepielski AM, McPeek MA. On the evidence for species coexistence: a critique of the coexistence program. Ecology. 2010;91:3153-64.

Silvertown J. Plant coexistence and the niche. Trends Ecol Evol. 2004;19:605-11.

Silvertown J, Biss PM, Freeland J. Community genetics: resource addition has opposing effects on genetic and species diversity in a 150-year experiment. Ecol Lett. 2009;12:165-70.

Silvestri S, Defina A, Marani M. Tidal regime, salinity and salt marsh plant zonation. Estuar Coast Shelf Sci. 2005;62:119-30.

Smith TW, Lundholm JT. Variation partitioning as a tool to distinguish between niche and neutral processes. Ecography. 2010;33:648-55.

Soberón J, Nakamura M. Niches and distributional areas: concepts, methods, and assumptions. Proc Natl Acad Sci U S A. 2009;106(Suppl 2):19644-50.

Stoll P, Prati D. Intraspecific aggregation alters competitive interactions in experimental plant communities. Ecology. 2001;82:319-27.

Tilman D. Resource competition and community structure. Princeton: Princeton university press; 1982.

Tilman D. The resource-ratio hypothesis of plant succession. Am Nat. 1985;125: 827-52.

Tilman D. Niche tradeoffs, neutrality, and community structure: a stochastic theory of resource competition, invasion, and community assembly. Proc Natl Acad Sci USA. 2004:101:10854-61.

Tilman D, Reich PB, Knops JMH. Biodiversity and ecosystem stability in a decadelong grassland experiment. Nature. 2006;441:629-32.

Tind K. Danmarks flora. Gyldendal: Copenhagen; 2003.

Tokeshi M. Species coexistence: ecological and evolutionary perspectives. Hoboken: Wiley; 2009

Torres JA. Niches and coexistence of ant communities in Puerto Rico: repeated patterns. Biotropica. 1984;16:284.

Tuomisto H, Ruokolainen L, Ruokolainen K. Modelling niche and neutral dynamics: on the ecological interpretation of variation partitioning results. Ecography. 2012;35:961-71.

Vandermeer J. Niche theory. Annu Rev Ecol Syst. 1972;3:107-32.

Vellend $\mathrm{M}$. The consequences of genetic diversity in competitive communities. Ecology. 2006;87:304-11.

Walter J, Jentsch A, Beierkuhnlein C, Kreyling J. Ecological stress memory and cross stress tolerance in plants in the face of climate extremes. Environ Exp Bot. 2013;94:3-8.

Weiher E, Freund D, Bunton T, Stefanski A, Lee T, Bentivenga S. Advances, challenges and a developing synthesis of ecological community assembly theory. Philos Trans R Soc B Biol Sci. 2011;366:2403-13.

Westerling AL, Turner MG, Smithwick EAH, Romme WH, Ryan MG. Continued warming could transform Greater Yellowstone fire regimes by mid-21st century. Proc Natl Acad Sci U S A. 2011;108:13165-70.
Whitlock R, Grime JP, Booth R, Burke T. The role of genotypic diversity in determining grassland community structure under constant environmental conditions. J Ecol. 2007;95:895-907.

Whittaker RH. Evolution of species diversity in land communities. Evol Biol. 1977; 10:1-67.

Wiens JA. On competition and variable environments. Am Sci. 1977;65:590-7.

Wright JS. Plant diversity in tropical forests: a review of mechanisms of species coexistence. Oecologia. 2002;130:1-14.

Zobel M. Plant species coexistence: the role of historical, evolutionary and ecological factors. Oikos. 1992;65:314.

\section{Publisher's Note}

Springer Nature remains neutral with regard to jurisdictional claims in published maps and institutional affiliations.
Ready to submit your research? Choose BMC and benefit from:

- fast, convenient online submission

- thorough peer review by experienced researchers in your field

- rapid publication on acceptance

- support for research data, including large and complex data types

- gold Open Access which fosters wider collaboration and increased citations

- maximum visibility for your research: over $100 \mathrm{M}$ website views per year

At BMC, research is always in progress.

Learn more biomedcentral.com/submissions 